\title{
Host Status of Rubus Species and Hybrids for the Root Lesion Nematode, Pratylenchus penetrans
}

\author{
Inga A. Zasada ${ }^{1}$ \\ USDA-ARS Horticultural Crops Research Unit, 3420 NW Orchard Avenue, \\ Corvallis, OR 97330
}

Patrick P. Moore

Washington State University-Puyallup, 2606 West Pioneer, Puyallup, WA 98371

Additional index words. plant-parasitic nematode, raspberry, resistance

\begin{abstract}
The root lesion nematode, Pratylenchus penetrans, is a production-limiting pest in red raspberry, Rubus idaeus. Genetic resistance, as a tool to manage $P$. penetrans in raspberries, would reduce the impact of this nematode on raspberry productivity as well as reduce the need for pre- and/or post-plant chemical treatments to keep populations in control. The host status of 11 Rubus species ( $R$. coreanus, $R$. crataegifolius, $R$. innominatus, $R$. leucodermis, $R$. niveus, $R$. parviflorus, $R$. parvifolius, $R$. pungens, $R$. spectabilis, $R$. sumatranus, and $R$. odoratus) for $P$. penetrans was evaluated in greenhouse studies. Additionally, hybrids of $R$. cockburnianus, $R$. lasiostylus, $R$. niveus, $R$. phoenicolasis, and $R$. sumatranus with $R$. idaeus 'Meeker' or 'Tulameen' were evaluated. The industry standard $R$. idaeus 'Meeker' was included in all trials as the control. Across trials, $R$. niveus and $R$. leucodermis were identified as poor hosts for $P$. penetrans. In addition, when another selection of $R$. niveus was evaluated in the final year of this study, it was also a poor host for P. penetrans. Among the remaining Rubus species materials tested, there were no consistent differences in host status for $P$. penetrans. It appears that $R$. niveus and $R$. leucodermis might be sources of resistance for $P$. penetrans. However, a hybrid between $R$. niveus and $R$. idaeus 'Tulameen' did not consistently support fewer $P$. penetrans than the 'Meeker' control. These results indicate that more research is needed to learn about the inheritance of the putative resistance.
\end{abstract}

Plant-parasitic nematodes were first reported in Rubus species in North America in the 1930s, when Pratylenchus species were associated with declining red raspberries (Rubus idaeus L.) (McElroy, 1992). Of the plant-parasitic nematodes associated with raspberry, Pratylenchus penetrans, the root lesion nematode, is the most economically important (McElroy, 1991). Feeding on roots by Pratylenchus penetrans (Cobb) Filipjev and Schuurmans Stekhoven can reduce the capacity of the plant to uptake nutrients and water. Pratylenchus penetrans was shown to cause $24 \%$ mortality of 'Willamette' red raspberry plants after 2 years (McElroy, 1977). In other studies, soil fumigation to control $P$. penetrans before planting red

\footnotetext{
Received for publication 1 May 2014. Accepted for publication 3 July 2014.

This research was partially funded through grants from the Northwest Center for Small Fruit Research and USDA-NIFA RAMP grant 2010-51101-21649. We thank Amy Peetz and Duncan Kroese of the USDA-ARS for technical assistance.

Mention of trademark, proprietary product, or vendor does not constitute a guarantee or warranty of the product by the U.S. Dept. of Agriculture and does not imply its approval to the exclusion of other products or vendors that also may be suitable.

${ }^{1}$ To whom reprint requests should be addressed; e-mail inga.zasada@ars.usda.gov.
}

raspberry dramatically increased yields (Seipp, 1986; Trudgill, 1986), and in one study, there was a $98 \%$ increase in yield of fumigated plots compared with non-fumigated plots containing $P$. penetrans in the first year of production (Bélair, 1991). Rate of decline will depend on the cultivar, but significant yield loss can occur when this nematode is left unchecked and population densities increase on raspberry plants.

Since the 1940s, growers have been able to manage plant-parasitic nematodes in raspberry by pre-plant soil fumigants and/or post-plant treatment with fenamiphos. In recent years, increased understanding of the negative environmental and health impacts of these compounds has led to restrictions or termination of their legal use. The registration for fenamiphos was cancelled in the United States [U.S. Environmental Protection Agency (EPA), 2008] and methyl bromide use in all U.S. commodities is in the process of being phased out. In addition, broadcast fumigation will become more burdensome with new EPA reregistration eligibility decisions (U.S. EPA, 2013); raspberry growers currently rely on a combination of 1,3-dichloropropene and chloropicrin for pre-plant fumigation. As a result, the raspberry industry is at a point in time when new, long-term, and economically viable
P. penetrans management strategies must be developed.

A key component of any integrated nematode management program is resistance. Having resistance as a tool to manage $P$. penetrans in raspberries would reduce the impact of this nematode on raspberry productivity as well as reduce the need for preand/or post-plant chemical treatments to keep this nematode in control. Although there are red raspberry breeding programs actively developing cultivars resistant to Phytophthora rubi and Raspberry Bushy Dwarf Virus, none are currently attempting to identify sources of resistance to $P$. penetrans, a significant production constraint to raspberry (Bélair, 1991; McElroy, 1977). Efforts have been made to evaluate raspberry cultivars for their reactions to $P$. penetrans (Bristow et al., 1980; Vrain and Daubeny, 1986). Rubus idaeus 'Newburgh', 'Chilcotin', 'Skeena', and 'Canby' were susceptible to $P$. penetrans, whereas the other tested cultivars, including 'Latham' and 'Matsqui', had varying levels of resistance to $P$. penetrans (Bristow et al., 1980). Vrain and Daubeny (1986) also screened several commercially available raspberry cultivars for their reaction to $P$. penetrans; 'Nootka' was the most resistant and 'Glen Clova' and 'Chilcotin' were the most susceptible; 'Meeker', 'Skeena', 'Willamette', and 'Haida' were intermediate in reaction. The most resistant material screened in this study was not from a $R$. idaeus cultivar, but rather from a Japanese accession of $R$. $\mathrm{cra}$ taegifolius. These results indicate that resistance might be more readily identified in Rubus species other than raspberry.

The long-term goal of this research program is to identify a source of resistance in Rubus species to $P$. penetrans that can be incorporated into a red raspberry cultivar of commercial quality. The objective of the experiment described here was to determine the host status of Rubus species and hybrids to $P$. penetrans.

\section{Materials and Methods}

Accessions of Rubus species were obtained by the Washington State University breeding program and used in crossability studies in 1996 and 1997 (Moore and Trople, 1999). The hybrids were planted in the field and evaluated for fertility, and only the most fertile hybrids were retained in the breeding program. Species and hybrids that were still available plus additional Rubus species accessions were evaluated for host status for $P$. penetrans in 2010-12 (Table 1). Generally, there was only a single genotype representing a species or hybrid. Rubus idaeus 'Meeker' was included as a control in each trial (Table 1). During each year of the study, tissue culture plants (clones) of Rubus species and hybrids were initiated from surface-sterilized shoots at Washington State University, Puyallup Research \& Extension Center, Puyallup, WA. The tissue culture plants were placed on rooting media and then rooted in a greenhouse. Approximately 3 months after 
Table 1. Sources and lineages of Rubus species and hybrids evaluated for host status to Pratylenchus penetrans.

\begin{tabular}{|c|c|}
\hline$\overline{\text { Entry }}$ & Source \\
\hline R. coreanus & PI 618519 \\
\hline R. crataegifolius & Jogkal $^{z}$ \\
\hline R. idaeus & Meeker $^{y}$ \\
\hline R. innominatus & PI 553646 \\
\hline R. leucodermis & Holden Village, WA-collected in 2005 by P. Moore \\
\hline$R$. niveus & PI 606461 \\
\hline R. niveus (WSU 2263 ) & $\left(\mathrm{PI} 618524 \times \mathrm{OP}^{\mathrm{w}}\right) \times \mathrm{OP}$ \\
\hline R. parviflorus & Puyallup, WA—collected in 1970 by B. Barritt \\
\hline R. parvifolius & Carbondale, IL—collected in 1973 by J.W. Hall \\
\hline R. pungens & PI 553849 \\
\hline R. spectabilis & Puyallup, WA—collected in 1970 by B. Barritt \\
\hline R. sumatranus & PI 618429 \\
\hline R. odoratus & Cunningham Falls, MD - collected in 1960 by R. Converse \\
\hline WSU 1414 & R. sumatranus (PI 618429) $\times$ Meeker \\
\hline WSU 1415 & R. sumatranus $(\mathrm{PI} 618429) \times$ Meeker \\
\hline WSU 1474 & Tulameen $\times R$. lasiostylus (PI 553670) \\
\hline WSU 1475 & Tulameen $\times R$. phoenicolasius (PI 553835) \\
\hline WSU 1479 & Tulameen $\times R$. cockburnianus (PI 618443) \\
\hline WSU 1673 & R. niveus $(\mathrm{PI} 606461) \times$ Tulameen \\
\hline
\end{tabular}

${ }^{\mathrm{z}}$ Hong et al. (1971); Vrain and Daubeny (1986).

'Fernández-Fernández et al. (2011).

${ }^{\mathrm{x}} \mathrm{WSU}=$ Washington State University raspberry breeding program, Puyallup, WA.

${ }^{\mathrm{w}} \mathrm{OP}=$ open-pollinated.

rooting, the tissue culture plants were transported to USDA-ARS Horticultural Crops Research Unit, Corvallis, OR, where they were transplanted into $3.7-\mathrm{L}$ pots containing a steam-pasteurized 1:2 sand:loam mix. Plants were allowed to establish in pots for $\approx 1$ month before inoculation with $P$. penetrans. During this time period plants were fertilized with $20 \mathrm{~N}-8.8 \mathrm{P}-16.6 \mathrm{~K}$ (J.R. Peters, Allentown, PA) twice a week and were grown in a greenhouse under long-day conditions (16-h photoperiod) with $26 / 18{ }^{\circ} \mathrm{C}$ day/night temperatures.

The $P$. penetrans population used in this experiment was obtained from a raspberry field in Lynden, WA, and maintained on raspberry and mint (Mentha piperita) in the greenhouse. Inoculum was obtained by extracting $P$. penetrans from roots under intermittent mist for $48 \mathrm{~h}$ (Ingham, 1994). At inoculation, $\approx 1800$ (2010) or 2500 (2011 and 2012) mixed-stage individuals of $P$. penetrans were inoculated into the root zone in $1-\mathrm{mL}$ aliquots placed in five $2.5-\mathrm{cm}$ deep holes made around the base of the plant. The holes were filled after inoculation. Each Rubus species or hybrid was replicated eight times in each of three trials and plants were arranged in a randomized block design. The experimental duration after nematode inoculation was $\approx 4$ months, during which time the plants were pruned and staked to manage growth and fertilized and grown in a similar environment as described previously.

At termination, the above-ground portion of the plant was removed and discarded. The contents of the pot were emptied onto a tray where the roots were shaken free of soil and a 50-g soil sample was collected and placed on a Baermann funnel and nematodes were extracted for 5 d (Ingham, 1994). Roots were washed free of soil and $P$. penetrans was extracted from the root system emanating from the original root ball by intermittent mist for 1 week (Ingham, 1994). The roots were then placed in a $70{ }^{\circ} \mathrm{C}$ oven for 1 week before determining dry weight. In 2010, the entire root system, including the original root ball, was weighed, whereas in 2011 and 2012, the original root ball was removed and only roots emanating from the original root ball were weighed. Pratylenchus penetrans recovered from soil and roots was enumerated using a dissecting microscope at $40 \times$ magnification and is expressed as number of $P$. penetrans per gram dry root and total number (soil plus root) of $P$. penetrans recovered per pot. In addition, reproduction factor $(\mathrm{RF}=$ final total $P$. penetrans population density/ initial $P$. penetrans population inoculation density) values were calculated.

Root weight and nematode data were $\log _{10}(\mathrm{x}+1)$ transformed before analysis to control for heteroscedasticity; non-transformed data are shown. Trials were analyzed separately. Data were then analyzed for effects of block and plant type using a mixed linear model analysis of variance (ANOVA) with block as a random factor and plant type as a fixed factor. Means were separated using Tukey's least significant differences $(P<0.05)$ (JMP 9.1; SAS Institute, Cary, NC).

\section{Results and Discussion}

We evaluated a diverse set of Rubus species in an attempt to identify a source of resistance to $P$. penetrans, which could potentially be introgressed into a commercially acceptable raspberry cultivar. There was a clone $\times$ trial interaction in the ANOVA, and therefore trials are presented separately (Table 2); however, similar trends were observed across trials. In all trials, $R$. niveus and $R$. leucodermis consistently supported the fewest total $P$. penetrans and $P$. penetrans/ gram root. The RF values for these species indicate that both are poor hosts for P. penetrans $(1>\mathrm{RF}>0$; Ferris et al., 1993). In $2010, R$. sumatranus and $R$. odoratus supported similarly low $P$. penetrans population densities as $R$. niveus and $R$. leucodermis. All of these species supported lower population densities of $P$. penetrans than $R$. idaeus 'Meeker', the most commonly planted cultivar in Washington (Peerbolt Crop Management, 2013). When RF values were considered, only $R$. innominatus and $R$. parviflorus would be considered good hosts $(10>\mathrm{RF}>1=$ good host $)$ for $P$. penetrans in 2010 (Table 2). In 2011, $R$. sumatranus had similarly low $P$. penetrans/ gram root as $R$. niveus and $R$. leucodermis; however, total $P$. penetrans was similar to those found in R. idaeus 'Meeker'. For R. odoratus, completely opposite results were observed in 2011 compared with 2010 with $R$. odoratus supporting the second highest total $P$. penetrans population densities of any Rubus species and considered a good host for $P$. penetrans. In 2012 , the same $R$. leucodermis selection evaluated in 2010 and 2011 continued to be resistant to $P$. penetrans. In addition, another selection of $R$. niveus, WSU 2263, was a similarly poor host for $P$. penetrans as $R$. niveus PI 606461.

In 2010 and 2011, we evaluated the same selection of $R$. crataegifolius, 'Jogkal' (Hong et al., 1971) that Vrain and Daubeny (1986) evaluated for resistance to $P$. penetrans. Our finding regarding the host status of $\mathrm{R}$. $\mathrm{Cra}$ taegifolius 'Jogkal' to $P$. penetrans was inconsistent across trials (Table 2). Vrain and Daubeny (1986) screened two R. crataegifolius selections, one from Japan and the other 'Jokgal' from Korea (Hong et al., 1971), both of which supported few $P$. penetrans with RF values less than 0.2 . These combined results indicate that $R$. crataegifolius may be a useful source of resistance to $P$. penetrans.

There were few consistent trends in root weight, which would explain the ability of a Rubus species to serve as a good or poor host. In 2010, the average dry root weight across Rubus species was $9.33( \pm 0.25) \mathrm{g}$. The Rubus species with the largest root systems were $R$. odoratus, $R$. leucodermis, $R$. sumatranus, and $R$. ideaus 'Meeker' with dry root weights ranging from $11.17( \pm 0.43) \mathrm{g}$ to $14.74( \pm 0.9)$ g. Rubus niveus had the smallest root system, $7.03( \pm 0.35) \mathrm{g}$, but was only different from the aforementioned species as well as $R$. innominatus. In 2011, the average dry root weight across Rubus species was $8.25( \pm 0.44)$ g. Similar to $2010, R$. odoratus had one of the largest root systems, 19.99 $( \pm 2.12) \mathrm{g}$, which was not different from $R$. innominatus and $R$. coreanus. Rubus parvifolius had the smallest roots system, $3.56( \pm 0.46) \mathrm{g}$, which was not different from the dry root weights of $R$. niveus, $R$. spectabilis, and $R$. pungens.

In addition to the Rubus species material, we evaluated a number of Rubus hybrids in 2011 and 2012 (Tables 1 and 2). The average dry root weights across hybrids were 6.18 $( \pm 0.35) \mathrm{g}$ and $4.08( \pm 0.21) \mathrm{g}$ in 2011 and 2012 , respectively. The $R$. phoenicolasius (WSU 1475) and R. cockburnianus (WSU 1479) hybrids did not differ from $R$. idaeus 'Meeker' in population densities of $P$. penetrans in roots and total number in either trial. 


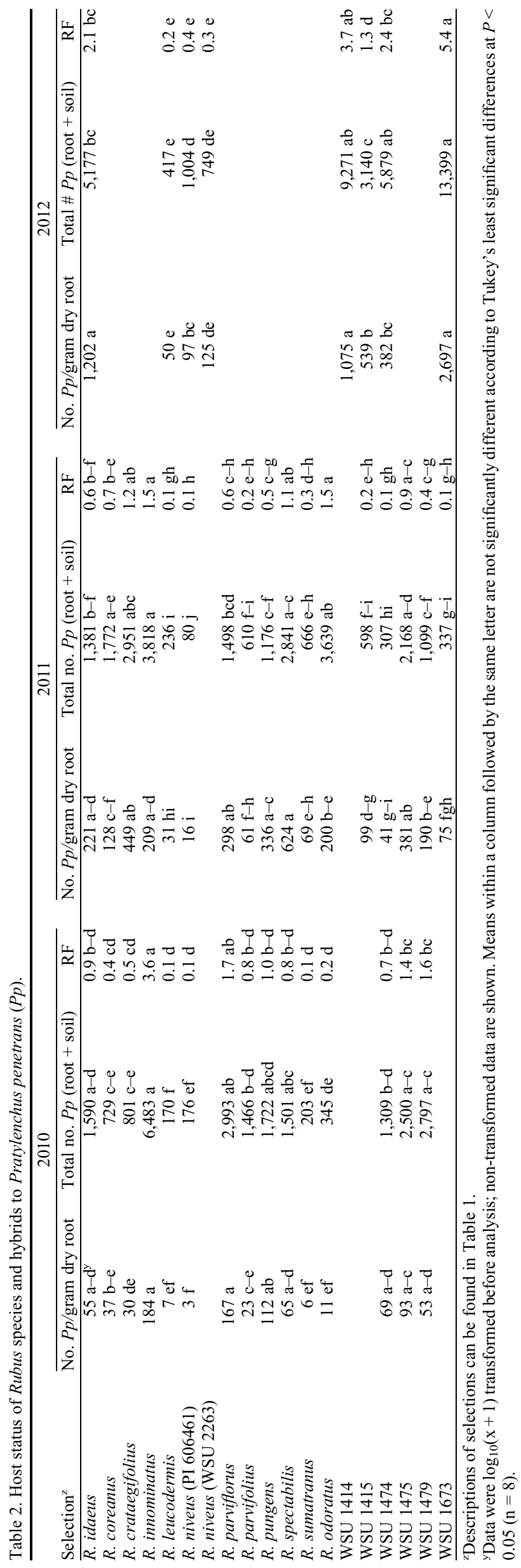

The $R$. lasiostylus (WSU 1474) and R. sumatranus (WSU 1414 and 1415) hybrids supported fewer $P$. penetrans than $R$. idaeus 'Meeker' in 2011 but high populations in 2012. WSU 1673 , a selection from the cross of $R$. niveus $\times R$. idaeus 'Tulameen', supported few $P$. penetrans in 2011 but very high densities in 2012. These combined results indicate that more research is needed to learn about the inheritance of the putative resistance.

The variability we observed across trials in final population densities of $P$. penetrans compared with initial population densities that have been reported by others. In our study, RF values for $P$. penetrans on 'Meeker' were $0.9( \pm 0.2), 0.6( \pm 0.1)$, and $2.1( \pm 0.2)$ in 2010, 2011, and 2012, respectively. When Vrain and Daubeny (1986) considered the host status of R. idaeus 'Willamette' to $P$. penetrans in greenhouse trials across years, RF values were $2.3,0.82$, and 0.86 . The host status of 'Meeker' to $P$. penetrans also varied across experimental venues with RF values of 1.7 and 0.20 in greenhouse and in microplots experiments (Vrain and Daubeny, 1986) and 1.3 in another greenhouse trial (Bristow et al., 1980). This observed variability across trials could be the result of a difference in environmental conditions and methodologies used in the experiments. Pratylenchus penetrans reproduces over a wide range of temperatures with a generation (egg to egg) requiring 46, 38, 28, 26 , and $22 \mathrm{~d}$ at $17,20,30,25$, and $27{ }^{\circ} \mathrm{C}$, respectively, under controlled conditions (Mizukubo and Adachi, 1997). The duration of three different experiments evaluating host status of Rubus species materials to P. penetrans was $\approx 100 \mathrm{~d}$ (Vrain and Daubeny, 1986), $110 \mathrm{~d}$ (Bristow et al., 1980), and 120 $\mathrm{d}$ (this study). Depending on the temperatures at which these experiments were conducted, anywhere from 2.6 to $5.5 P$. penetrans generations could have occurred based on constant temperatures of 17 and $27{ }^{\circ} \mathrm{C}$, respectively (Mizukubo and Adachi, 1997). Another difference could be initial inoculation densities used across experiments. In the aforementioned studies, initial inoculation densities ranged from 2.2 to $4.0 P$. penetrans/ $\mathrm{g}$ soil (Vrain and Daubeny, 1986), 5.0 P. penetrans/g soil (Bristow et al., 1980), and 0.7 to $1.0 P$. penetrans $/ \mathrm{g}$ soil in our study. However, inoculation density does not seem to be a plausible explanation for the variation because the lowest RF value reported for 'Willamette' by Vrain and Daubeny (1986), 0.82 , occurred when plants were inoculated with the highest initial population density (4.0 $P$. penetrans/g soil). In fact, in our study, when the same initial inoculation density was used in 2011 and 2012 (1.0 P. penetrans/g soil), RF values were 0.6 and 2.1 on $R$. idaeus 'Meeker', respectively.

Pratylenchus penetrans is a significant production constraint in raspberry and having a commercially acceptable cultivar with resistance to $P$. penetrans would be a useful tool for raspberry growers to combat this pest. Our research demonstrates that some 
sources of $R$. niveus and $R$. leucodermis are poor hosts for $P$. penetrans and may provide a source of resistance genes that can be transferred to red raspberry. There was minimal sampling of variability within Rubus species and resistance may be present in specific accessions of other species. In addition, our results indicate that more research is needed to learn about the inheritance of the putative resistance. To truly understand the potential of $R$. niveus and $R$. leucodermis as sources of resistance, these species should evaluated in the field.

\section{Literature Cited}

Bélair, G. 1991. Effect of preplant soil fumigation on nematode population densities and on growth and yield of raspberry. Phytoprotection 72:21-25.

Bristow, P.R., B.H. Barritt, and F.D. McElroy. 1980. Reaction of red raspberry clones to root lesion nematode. Acta Hort. 112:39-43.

Fernández-Fernández, F., L. Antanaviciute, C.L. Govan, and D.J. Sargent. 2011. Development of a multiplexed microsatellite set for fingerprinting red raspberry (Rubus idaeus) germplasm and its transferability to other Rubus species. J. Berry Res. 1:177-187.
Ferris, H., H.L. Carlson, D.R. Viglierchio, B.B. Westerdahl, F.W. Wu, C.E. Anderson, A. Juurma, and D.W. Kirby. 1993. Host status of selected crops to Meloidogyne chitwoodi. J. Nematol. 25:849-857.

Hong, S.B., D.K. Lee, Y.H. Kim, J. Kong, S.D Oh, and J.H. Kim. 1971. Characteristics of 7 Korean raspberry lines (Rubus crataegifolius) selected as recommendable in Korea. The Research Reports of the Office of Rural Development, Suwon, Korea (South) 14:5155.

Ingham. 1994. Nematodes, p. 459-490. In: Weaver, R.W., S. Angle, P. Bottomley, B. Bezdicek, S. Smith, A. Tabatabai, and A. Wollum (eds.). Methods of soil analysis. Part 2. Microbiological and biochemical properties no. 5. Soil Science Society of America Press, Madison, WI.

McElroy, F.D. 1977. Effect of two nematode species on establishment, growth, and yield of raspberry. Plant Dis. Rpt. 61:277-279.

McElroy, F.D. 1991. Nematode parasites, p. 59-62. In: Ellis, M.A., R.H. Converse, R.N. Williams, and B. Williamson (eds.). Compendium of raspberry and blackberry diseases and pests. APS Press, St. Paul, MN.

McElroy, F.D. 1992. A plant health care program for brambles in the Pacific Northwest. J. Nematol. 24:457-462.
Mizukubo, T. and H. Adachi. 1997. Effect of temperature on Pratylenchus penetrans development. J. Nematol. 29:306-314.

Moore, P.P. and D.D. Trople. 1999. Crossability of Rubus species in the WSU Breeding Program. Acta Hort. 505:357-362.

Peerbolt Crop Management. 2013. Small fruit update. 15 Jan. 2014. <http://www.berriesnw. com/SFU/2013/44-SFU10-29-13.pdf $>$.

Seipp, D.C. 1986. Controlling of replant problems in red raspberries by soil desinfestation. Acta Hort. 183:223-229.

Trudgill, D.L. 1986. Effect of soil treatments for the control of Pratylenchus penetrans (Nematoda) on the growth and yield of raspberry (Rubus idaeus) in eastern Scotland. Crop Res. 26:89-109.

U.S. Environmental Protection Agency. 2008. Fenamiphos; product registration cancellation order. 18 Dec. 2013. <http://www.epa.gov/ fedrgstr/EPA-PEST/2008/June/Day-18/p13623. pdf $>$.

U.S. Environmental Protection Agency. 2013. Implementation of risk mitigation measures for soil fumigant pesticides. 18 Dec. 2013. $<$ http://www.epa.gov/pesticides/reregistration/ soil_fumigants $/>$.

Vrain, T.C. and H.A. Daubeny. 1986. Relative resistance of red raspberry and related genotypes to the root lesion nematode. HortScience 21:1435-1437. 